\title{
A comparison between direct and pan-derived measurements of the isotopic composition of atmospheric waters
}

\author{
C.S. Azcurra $^{\text {a }}$, C.E. Hughes ${ }^{\text {b }}$, S. Parkes ${ }^{\text {b }}$, S.E. Hollins ${ }^{\text {b }}$, J.J. Gibson ${ }^{\text {c }}$, M.F. McCabe a and J.P. Evans ${ }^{\text {d }}$ \\ ${ }^{a}$ University of New South Wales, School of Civil \& Environmental Engineering, Sydney, NSW 2052 Australia \\ ${ }^{b}$ Institute for Environmental Research, Australian Nuclear Science and Technology Organisation (ANSTO), \\ Menai, NSW 2234, Australia \\ ${ }^{c}$ Alberta Innovates Technology Futures, University of Victoria, 3-4476 Markham Street, Victoria BC V8N \\ 5 C8 Canada \\ ${ }^{d}$ University of New South Wales, Climate Change Research Centre, Sydney, NSW 2052 Australia \\ Email: c.azcurra@unsw.edu.au
}

\begin{abstract}
The stable isotopes of water can be used to examine and quantify the contribution to atmospheric moisture from evaporation, transpiration and surface-waters. However, obtaining extensive and ongoing time series data of the isotopic composition of atmospheric moisture has been difficult. Presented here is an alternate method using an isotope mass balance approach to estimate the isotopic composition of atmospheric moisture using water samples collected from class A evaporation pans. While this evaporation pan method does not provide the high-resolution time series data that can be obtained from an isotope analyser taking in-situ measurements of atmospheric moisture, the method is relatively simple and inexpensive to set-up and maintain.

In this preliminary investigation, a comparison between the isotopic composition of atmospheric moisture estimated from the evaporation pan method and in-situ measurements of the isotopic composition of water vapour using a Fourier Transform Infrared (FTIR) spectrometer deployed at the Lucas Heights weather station in New South Wales is undertaken. Through comparison of the two series of hydrogen isotope data, an assessment of the evaporation pan method can be made. Although there was some agreement between the isotopic composition of vapour measured by the FTIR spectrometer and the estimation for the atmospheric moisture $\left(\mathrm{R}^{2}=0.49\right)$, the comparison is sensitive to climatic parameters that vary significantly within a 24hour period such as the relative humidity of air and the air and pan temperatures. Inverting the model to use the FTIR spectrometer measurements at an hourly resolution improved the performance of the model $\left(\mathrm{R}^{2}=\right.$ 0.57). However, this also revealed that the model produced more depleted values of the evaporation pan water isotopes than those observed. In contrast, there was a variable relationship between the modelled and observed isotope values of atmospheric moisture. These conflicting results will need to be resolved before the evaporation pan method is broadly applied in isotope hydrology.
\end{abstract}

Keywords: Stable isotope hydrology, atmospheric moisture, evaporation, deuterium 


\section{INTRODUCTION}

The stable isotopes of water $\left(\mathrm{H}_{2}{ }^{16} \mathrm{O}, \mathrm{H}_{2}{ }^{18} \mathrm{O}\right.$ and $\left.\mathrm{HD}^{16} \mathrm{O}\right)$ can be used to track moisture as it moves through the hydrological cycle - when combined with other measurements of water fluxes and volumes, they can provide information on water sources and movement suitable for producing water and energy balances. In order to close these balances, all aspects of the water cycle need to be measured and monitored. However, a complete understanding of the spatial and temporal characteristics of the isotopic composition of atmospheric moisture has so far been difficult to obtain.

The isotopic composition of atmospheric moisture can influence the isotopic composition of evaporated and transpired waters. It will vary with the origin of the moisture in an air-mass, and can be further modified by fractionation due to rainout and re-evaporation of raindrops or surface waters, or by mixing with other air masses. While global networks exist for monitoring the stable isotopes of water in precipitation and rivers, there is no equivalent network for atmospheric moisture that provides a similar level of coverage.

One limiting factor of a global atmospheric moisture network is that measuring the isotopic composition of water vapour can be difficult (Gibson et al., 1999). While measurements obtained through the use of vapour traps may not be temporally or spatially representative of atmospheric moisture, recent advances in optical methods offer the opportunity to directly measure vapour samples in situ.

Although these stable isotope instruments for vapour analysis can be deployed in the field, they may not be suitable for remote applications, and the application of these instruments to produce an atmospheric isotope network may not be cost-effective. The Craig-Gordon model (Craig and Gordon, 1965) for the isotopic composition of evaporated moisture requires the isotopic composition of 'free air' (denoted as $\delta_{A}$, and described to be unaffected by the evaporation) as an input. By combining this model with a mass balance approach, Gibson et al. (1999) proposed an alternative method for determining the isotopic composition of atmospheric moisture using liquid samples and readily available meteorological variables. Such an approach would allow greater coverage of atmospheric isotope measurements given that evaporation pans already exist worldwide.

This study compares the $\delta_{A}$ estimated from the evaporation pan method with the isotopic composition of water vapour measured in-situ using a Fourier Transform Infrared (FTIR) deployed spectrometer at the Lucas Heights weather station in New South Wales, Australia. This preliminary study assesses the performance of the pan-derived $\delta_{A}$ estimation method, identifies parameters that significantly affect the estimated panderived $\delta_{A}$ and proposed means by which to improve the pan-derived $\delta_{A}$ estimations.

\section{THEORY}

Craig and Gordon (1965) developed a model for the isotopic fractionation of water during evaporation, where the isotopic composition of the evaporate water $\delta_{E}$ is estimated as

$$
\delta_{E}=\frac{\delta_{L}-h \delta_{A}-\varepsilon}{1-h+\varepsilon_{K}} .
$$

The estimation requires the isotopic composition of the liquid being evaporated $\delta_{L}$, the isotopic composition of 'free air' $\delta_{A}$, the relative humidity of the air/water interface $h$ (normalised to the temperature of the water), and the isotopic fractionation factors for equilibrium enrichment $\varepsilon^{*}$ and kinetic enrichment $\varepsilon_{K}$ (total enrichment $\varepsilon$ is the summation of the two enrichment factors $\varepsilon^{=} \varepsilon^{*}+\varepsilon_{K}$ ). Most of these parameters can be determined directly (i.e. $\delta_{L}$ ) or indirectly ( $h$ requires the relative humidity of the air $h_{\text {air }}$ along with the pan water and air temperatures $T_{p a n}$ and $T_{a i r}, \varepsilon^{*}$ can be approximated as a function of air temperature, while $\varepsilon_{K}$ is proportional to the humidity gradient between the liquid and unsaturated air). However, like $\delta_{E}, \delta_{A}$ is not routinely measured. Combining Eq. (1) with water- and mass-balances allows these unknowns to be determined.

For a well-mixed evaporation pan with a constant density of water and no overflow, the water and isotope mass balances can each be described by

$$
\begin{gathered}
\frac{d V}{d t}=I-E \\
\frac{d\left(V \delta_{L}\right)}{d t}=I \delta_{I}-E \delta_{E}
\end{gathered}
$$


where $V$ is the volume of the reservoir, $d V$ is the change in volume over the time period $d t, I$ is the inflow volume, $E$ is the evaporation volume, and $\delta_{L}, \delta_{I}$ and $\delta_{E}$ are the isotopic compositions of the evaporation pan, inflow and evaporated water, respectively. Combining Eq. (1) and Eq. (3) produces

$$
V \frac{d \delta_{L}}{d t}+\delta_{L} \frac{d V}{d t}=\delta_{I} I-\left(\frac{\delta_{L}-h \delta_{A}-\varepsilon}{1-h-\varepsilon_{K}}\right) E
$$

Solutions to Eq. (4) exist for three water balance scenarios:

1. When the pan receives no inflow (referred to as the 'drying pan' scenario)

2. When the pan receives inflow but still has a change in volume (either $I<E$ or $E<I$; the "drying pan with input' scenario)

3. When the pan receives the same amount of water as has been evaporated $(I=E$; the 'constant volume pan' scenario).

The solutions have been derived elsewhere (refer to the work of Gibson et al., 1999 and Gonfiantini, 1986) and are reiterated in the following sections. For all scenarios, the water is assumed to be well-mixed with a constant density of water.

\subsection{The drying pan}

This is the simplest of the three scenarios, where changes in the pan volume are exclusively a result of evaporation. With the initial pan volume denoted as $V_{0}$ and the residual volume of the pan as $f=V / V_{0}$, Eq. (3) can be rearranged as

$$
\frac{d \delta_{L}}{d(\ln f)}=\delta_{E}-\delta_{L}
$$

Eq. (1) can then be substituted into Eq. (5) and the resulting equation integrated to produce

$$
\delta_{L}=\delta^{*}-\left(\delta^{*}-\delta_{0}\right) f^{m}
$$

where $\delta^{*}=\left(h \delta_{A}+\varepsilon\right) /(h-\varepsilon)$ is the limiting isotopic composition of the pan water due to local atmospheric conditions (Craig and Gordon, 1965; Gat and Levy, 1978), $\delta_{0}$ is the initial isotopic composition of the pan water and $m=(h-\varepsilon) /\left(1-h+\varepsilon_{K}\right)$ as defined by Welhan and Fritz (1977).

\subsection{The drying pan with input}

A drying pan may receive some input, such as precipitation, during a time period, making Eq. (5) redundant for this scenario. In order to account for the input, an alternative expression for $\delta_{L}$ is defined

$$
\delta_{L}=\delta_{S}-\left(\delta_{S}-\delta_{0}\right) f^{-(1+m x) /(1-x)}
$$

where $\delta_{S}=\left(\delta_{I}+m x \delta^{*}\right) /(1+m x)$ is the isotopic composition the pan water approaches as $f$ decreases to zero (note that $\delta_{S}$ approaches $\delta^{*}$ as the input decreases and $\delta_{S}$ approaches $\delta_{I}$ as evaporation decreases), and $x=E / I$ is the ratio of evaporation to inflow.

\subsection{The constant volume pan}

In the case of the constant volume pan, the amount of inflow is the same as the evaporation over a time period (i.e. $I=E$ ), and so $d V / d t=0$. In this scenario, Eq. (3) becomes

$$
\frac{d \delta_{L}}{d t}=\left(\delta_{I}-\delta_{E}\right) \frac{I}{V}
$$

Combining Eq. (1) with Eq. (8) and integrating produces

$$
\delta_{L}=\delta_{S}-\left(\delta_{S}-\delta_{0}\right) e^{-(1+m) \frac{I t}{V}} .
$$

\section{METHOD}

The evaporation pan was set up at the Lucas Heights weather station in New South Wales, Australia $\left(34.05^{\circ} \mathrm{S}, 150.98^{\circ} \mathrm{E}\right)$ along with a Fourier Transform Infrared (FTIR) spectrometer taking vapour measurements at a height of $10 \mathrm{~m}$. Only the hydrogen isotopes $\left({ }^{1} \mathrm{H}\right.$ and ${ }^{2} \mathrm{H}$, where the relative abundance of 
each isotope is represented using the delta notation $\delta^{2} \mathrm{H}$ and normalised to the VSMOW standard) are considered in this work.

\subsection{Evaporation pan}

The evaporation pan at Lucas Heights has been operated for a number of years, including during the time period for this study from $23^{\text {rd }}$ June 2009 to $16^{\text {th }}$ February 2010 . The pan is topped up (or bailed if necessary) at $9 \mathrm{am}$ each day with water from the mains supply to maintain a volume of $170 \mathrm{~mm}$. Two $30 \mathrm{~mL}$ samples for each of the pan and feed waters were taken for isotopic analysis at regular intervals of between six and eight days (typically seven). Evaporation pan cleaning occurred three times during the study period (on days 29, 105 and 183), where a substantial proportion of the pan water was replaced with feed water. Precipitation at the weather station was also collected over the same time intervals, producing a composite sample for the interval. When possible, two $30 \mathrm{~mL}$ samples of this water were also collected for isotopic analysis. Instrumentation at the site included relative humidity, air temperature and rainfall (measured at 15 minute intervals) and pan temperature (measured every hour).

Water samples were analysed for both $\delta^{2} \mathrm{H}$ and $\delta^{18} \mathrm{O}$ by use of either Infrared Mass Spectrometry (IRMS) or Picarro Cavity Ring-Down spectrometry, with a measurement precision $(1 \sigma)$ of $<2 \%$ and results normalised to the VSMOW standard. Selected samples were also analysed on a Los Gatos Spectrometer to assess consistency between the IRMS and Picarro.

\subsection{FTIR spectrometer}

A low resolution FTIR spectrometer deployed at Lucas Heights was used to collect in-situ measurements of the stable isotopes in water vapour $\left(\delta_{\text {FTIR }}\right)$. During the monitoring period the FTIR sampled air through heated sampling lines from a height of $10 \mathrm{~m}$. The FTIR collects spectra continuously at a rate of approximately $2 \mathrm{hz}$, however, at this sampling rate the precision of the measurements are very poor. Averaging scans over 1 hour gives a measurement precision $(1 \sigma)$ of $<0.5 \%$ for $\delta^{2} \mathrm{H}$ at mixing ratios between 30000 and 5000 ppm. For comparison with the $\delta_{A}$ calculated from evaporation pan sampling program, the mean of all FTIR measurements collected between evaporation pan samples was calculated. The hourly data were also used as an input to calculate $\delta_{L}$.

\subsection{Estimation of $\boldsymbol{\delta}_{\mathrm{A}}$ from pan measurements}

The evaporation pan at Lucas Heights can be modelled as a constant volume pan when considering time intervals of whole days. Relative humidity, and air and pan temperature data were arithmetically averaged over daily periods to coincide with the daily topping up or bailing of pan water. Daily equilibrium and kinetic fractionation factors ( $\varepsilon^{*}$ and $\varepsilon_{K}$, respectively) were subsequently calculated from these values. $\varepsilon^{*}$ was estimated from its relationship with temperature $\left(\varepsilon^{*}=1-\alpha^{-1}\right.$, where $\left.\ln (\alpha)=A T^{2}+B T^{1}+C\right)$, using the experimentally derived values from Majoube (1971) for the coefficients of the equation (where $T$ is in Kelvin). $\varepsilon_{K}$ was estimated using the humidity-dependent expression of Gonfantini (1986) [here $\varepsilon_{K}=12.5(1-$ $h)$ for $\left.\delta^{2} H\right]$. An approximately weekly average was then produced for all parameters over time intervals defined by the sampling of water for isotopic analysis. These weekly resolution data were used to estimate $\delta_{A}$.

\subsection{Estimation of $\delta_{L}$ from vapour measurements}

To test the pan-derived $\delta_{A}$ model at a higher temporal resolution, the hourly $\delta_{F T I R}$ measurements were used in place of $\delta_{A}$ to estimate $\delta_{L}$. The 15-minute measurements of meteorological variables were combined to produce data that coincided with the $\delta_{F T I R}$ data set. Evaporation loss estimated from the daily volume adjustment to the evaporation pan was evenly distributed throughout the 24-hour period. While precipitation volumes were available for 15-minute intervals, the isotopic composition for each incidence of rainfall was not - so the weekly composite values were applied. The volume of water was reset to $170 \mathrm{~mm}$ at $9 \mathrm{am}$ each day.

\section{RESULTS AND DISCUSSION}

\subsection{Pan-derived $\boldsymbol{\delta}_{\mathrm{A}}$}

The evaporation pan samples revealed the gradual enrichment of the isotopic composition of the pan water between sampling events (Figure 1), with sudden depletions representing weeks where the pan was cleaned and part or all of the water replaced with the relatively isotopically depleted feedwater. $\delta^{2} \mathrm{H}$ values for 
weekly precipitation ranged from $-74.9 \%$ to $16.41 \%$, and samples for the study period produced a local meteoric water line of $\delta^{2} \mathrm{H}=8.23 \times \delta^{18} \mathrm{O}+15.02$.

The pan-derived $\delta_{A}$ time series is also presented in Figure 1, along with $\delta_{F T I R}$ measurements averaged over the same time intervals. The two time series show some similarities (a general enrichment trend with periods of isotopic depletion around day 130 and during days 180 to 190) but also numerous discrepancies. Figure 2 shows only some agreement between the observed and modelled values $\left(R^{2}=0.49\right)$, which may be a result of the FTIR spectrometer measurements being at $10 \mathrm{~m}$ and not representative of the 'free air' as defined in the Craig and Gordon (1965) model.

A simple sensitivity analysis was performed by changing the magnitude of measurements by their variability (the standard deviation for each day of the study period relative to the average daily mean values for $h_{\text {air }}, T_{\text {air }}$ and $\left.T_{p a n}\right)$ or their uncertainty $(10 \%$ applied to volumetric measurements, an absolute difference of $2 \%$ for isotope values) and observing the relative change in $\delta_{A}$. Three parameters $\left(h_{\text {air }}, T_{\text {air }}\right.$ and $\left.T_{\text {pan }}\right)$ had a much greater influence on $\delta_{A}$ than the others (Table 1) as these determine both the equilibrium and kinetic enrichment factors.

\section{2. $\delta L$ from FTIR data}

In order to evaluate if the pan-derived $\delta_{A}$ modelling could be improved by using data at a higher temporal resolution, the model was inverted to estimate the isotopic composition of the pan water $\left(\delta_{L M}\right)$ using the hourly $\delta_{F T I R}$ values in place of $\delta_{A}$ measurements. All three scenarios described in Section 2 applied to this model, depending on the amount of water received by and evaporated from the evaporation pan during each hour.
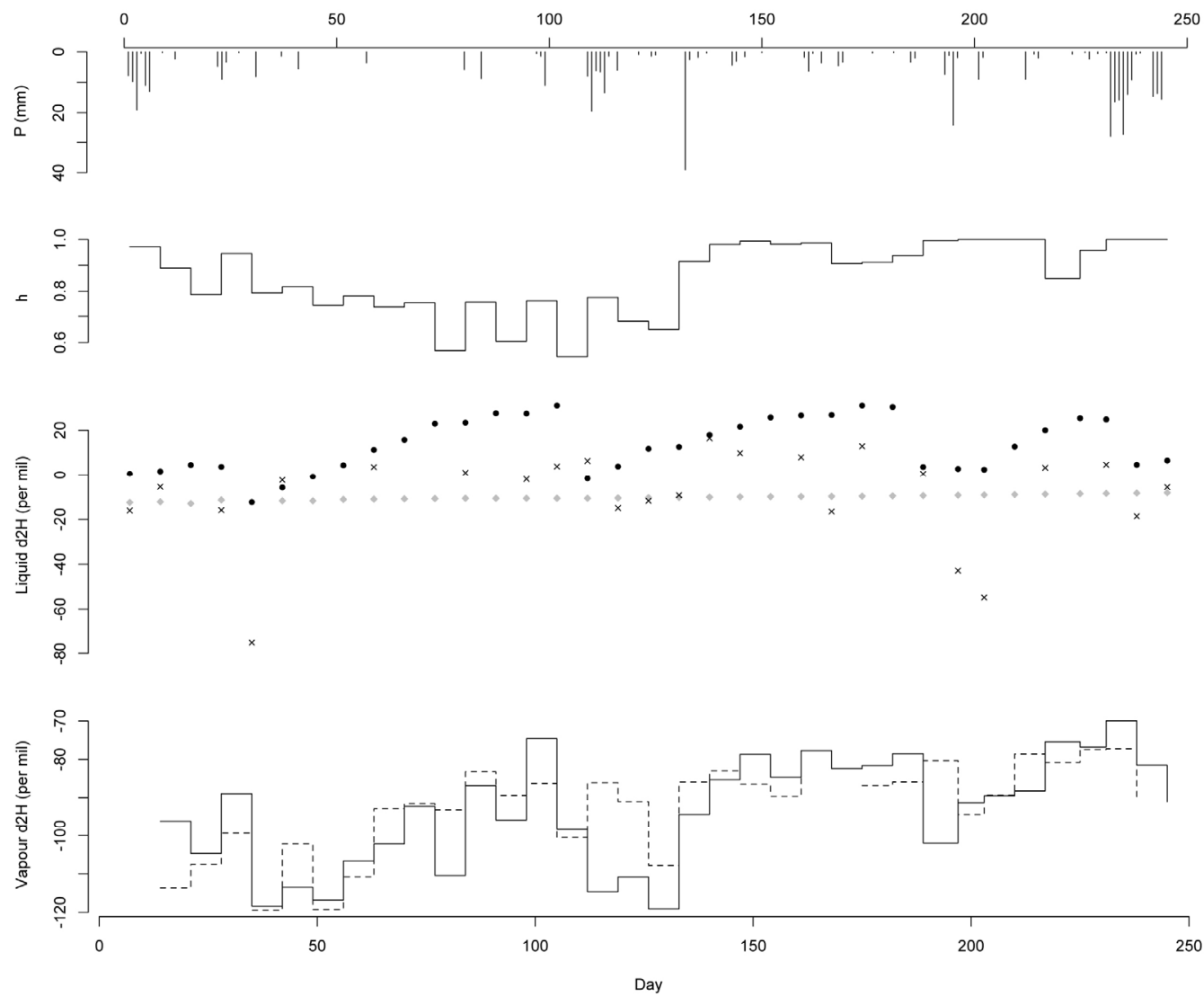

Figure 1. Time series of daily precipitation $P$, mean relative humidity for the sampling interval $h, \delta^{2} \mathbf{H}$ of pan water $\delta_{L}$ (circles), input waters - precipitation (crosses) and feedwater (diamonds), pan-derived $\delta_{A}$ at approximately weekly intervals (solid line) and average $\delta_{F T I R}$ for the same time intervals (broken line). 
Table 1. Mean absolute difference in pan-derived $\delta_{A}$ due to changes in magnitude (a decrease or increase based on uncertainty or variability) of measured parameters.

\begin{tabular}{lcccccccc}
\hline & $\delta_{\text {Feedwater }}$ & $\delta_{\text {Precipitation }}$ & $\delta_{\text {Pan-water }}$ & $V_{\text {Top-up }}$ & $V_{\text {Precipitation }}$ & $T_{\text {air }}$ & $T_{\text {pan }}$ & $h_{\text {air }}$ \\
\hline Decrease & 0.60 & 0.16 & 2.53 & 0.10 & 0.07 & 24.93 & 15.44 & 19.27 \\
Increase & 0.60 & 0.16 & 2.53 & 0.08 & 0.07 & 17.57 & 21.44 & 12.34 \\
\hline
\end{tabular}

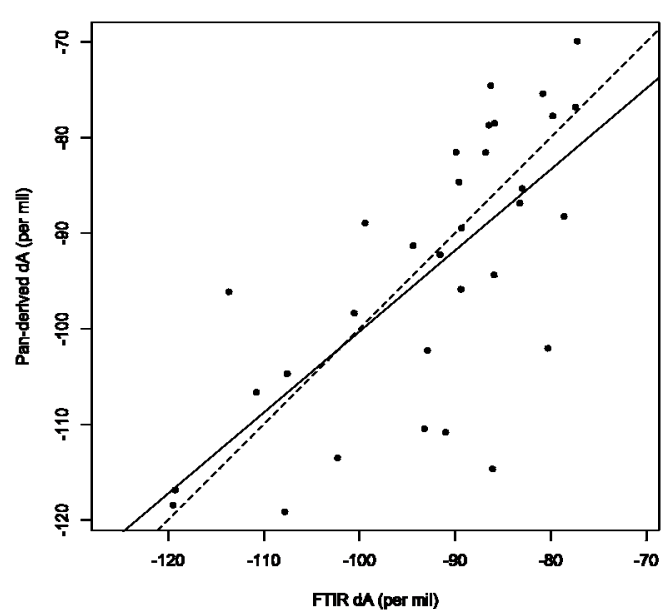

Figure 2. Plot of pan-derived $\delta_{A}$ versus average $\delta_{F T I R}$ for the same time intervals. Also shown are a trendline for the correlation between data sets (solid line, $\left.\mathbf{R}^{2}=0.49\right)$ and a 1:1 line (broken line).
Figure 3 shows how the vapour-derived pan water $\delta_{L M}$ compares with the grab samples taken at weekly intervals. The $\delta_{L M}$ time series retains the general trends from the observed $\delta_{L}$, but a bias exists in the model where it produces more depleted values than observed. Solutions with alternative simplifications exist for Eq. (4) and their use may reduce this bias.

The correlation between $\delta_{L M}$ and observed $\delta_{L}$ (Figure $4, \mathrm{R}^{2}=0.57$ ) is better than the correlation between $\delta_{A}$ and $\delta_{F T I R}$. This suggests that arithmetic averaging of parameters (such as $h_{\text {air }}$. $T_{\text {air }}$ and $T_{\text {pan }}$, which all vary diurnally) may contribute to the error in the weekly pan-derived $\delta_{A}$. The use of $\delta_{F T I R}$ measurements in place of $\delta_{A}$ would also introduce uncertainty into the $\delta_{L M}$ estimates.

While the liquid measurements were generally more isotopically enriched than the modelled $\delta_{L}$, the pan-derived $\delta_{A}$ had a variable relationship with the $\delta_{F T I R}$ observations. It will be interesting to see if using the oxygen isotopes $\left({ }^{16} \mathrm{O} /{ }^{18} \mathrm{O}\right)$ with the model (and its inverted arrangement) also produce the same conflicting results.

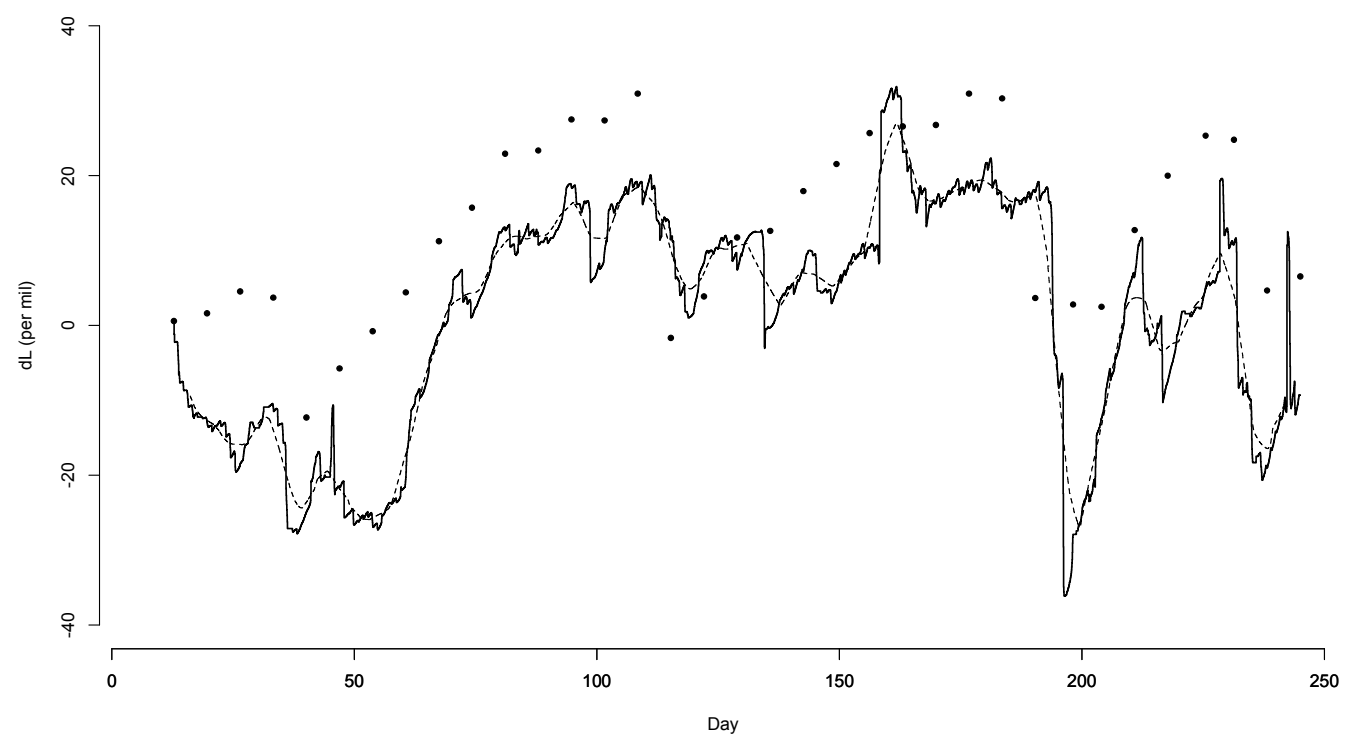

Figure 3. Time series of estimated $\delta_{L}$ at hourly intervals (solid line), as a weekly moving average (thin broken line) and observed $\delta_{L}$ as determined by approximately weekly grab samples (circles). 


\section{CONCLUSIONS}

The research presented here assessed the application of the Craig and Gordon (1965) model of evaporated moisture to estimate $\delta_{A}$ from evaporation pan measurements. It was found that the method is most sensitive to the input parameters describing the relative humidity of air, and the air and pan temperatures: all parameters that vary significantly within a 24 hour period and that have the greatest impact on the fractionation factors in Craig-Gordon model.

The model was inverted using the FTIR vapour measurements and ancillary data available at a higher temporal resolution, in order to estimate the isotopic composition of pan water. While agreement between the modelled and observed data sets was good $\left(\mathrm{R}^{2}=0.57\right)$, further work is required to identify the sources of error that lead to discrepancies between the time series and between the two model arrangements. Part of this further work will include a comparison between alternative solutions to Eq. (4) and an assessment of the model performance using the oxygen isotopes $\left({ }^{16} \mathrm{O} /{ }^{18} \mathrm{O}\right)$.

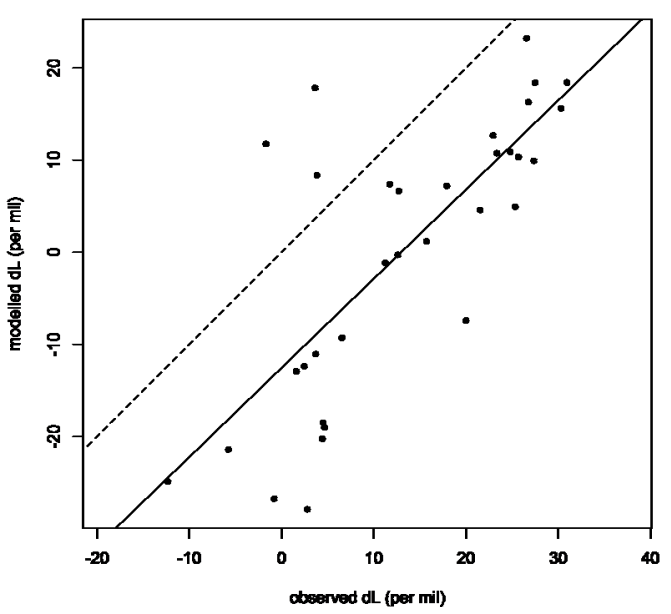

Figure 4. Plot of estimated $\delta_{L}$ versus observed $\delta_{L}$ from the hourly output. Also shown are a trendline for the correlation between data sets (solid line, $R^{2}=0.57$ ) and a 1:1 line (broken line).

\section{ACKNOWLEDGMENTS}

We wish to thank Chris Dimovski and Jagoda Crawford and many other ANSTO staff from time to time for collecting the weekly samples, as well as Leisa Dyer and others from the Environmental Monitoring section for 15 minute and daily meteorological data. Cecilia Azcurra is supported by top-up scholarships from the University of New South Wales and the National Centre for Groundwater Research and Training.

\section{REFERENCES}

Craig, H. and Gordon, L.I. (1965). Deuterium and oxygen 18 variations in the ocean and the marine atmosphere. In E. Tongiogi (ed.) Stable Isotopes in Oceanographic Studies and Paleotemperatures, pp. 9130, Laboratorio di Geologia Nucleare, Pisa.

Gat, J.R. and Levy, Y. (1978). Isotope hydrology of inland sabkhas in the Bardawil area, Sinai. Limnology and Oceanography, 23, 841-850.

Gibson, J.J., Edwards, T.W.D., and Prowse, T.D. (1999). Pan-derived isotopic composition of atmospheric water vapour and its variability in northern Canada. Journal of Hydrology, 217, 55-74.

Gonfiantini, R. (1986). Environmental isotopes in lake studies. In P. Fritz and J. Fontes (ed.), Handbook of environmental isotope geochemistry vol. 2., pp. 113-168, Elsevier, Amsterdam.

Loescher, H. W., Jacobs, J. M., Wendroth, O., Robinson, D. A., Poulos, G. S., McGuire, K., Reed, P., Mohanty, B. P., Shanley, J. B. and Krajewski, W. 2007. Enhancing water cycle measurements for future hydrologic research. Bulletin of the American Meteorological Society. 88, 669-676.

Majoube, M. (1971). Fractionnement en oxygène 18 et en deutérium entre l'eau et sa vapeur, Journal de Chimie Physique, 197, 1423-1436.

Wagener, T., Sivapalan, M., Troch, P. A., McGlynn, B. L., Harman, C. J., Gupta, H. V., Kumar, P., Rao, P. S. C., Basu, N. B. and Wilson, J. S. 2010. The future of hydrology: An evolving science for a changing world. Water Resources Research. 46.

Welhan, J.A. and Fritz, P. (1977). Evaporation pan isotopic behavior as an index of isotopic evaporative conditions, Geochimica et Cosmochimica Acta, 41, 682-686. 